\title{
A cadaveric study of variations in the vertebrobasilar system
}

\author{
Sunitha Narayanan ${ }^{1}$, Geetha $\mathbf{G N}^{2, *}$ \\ 1,2 Associate Professor, Dept. of Anatomy, Academy of Medical Sciences, Pariyaram, Kannur, Kerala, India
}

*Corresponding Author: Geetha GN

Email: gdruhin@gmail.com

Received: $18^{\text {th }}$ June, 2018

Accepted: $12^{\text {th }}$ July, 2018

\begin{abstract}
Introduction: The intracranial part of vertebral artery, basilar artery, and their branches together form the veretebrobasilar system. Identification of anomalies or variations in the vertebrobasilar system can be useful in diagnosing associated aneurysms, and in preventing complications during endovascular treatment.

Materials and Methods: The study was conducted in 60 randomly selected brain specimens obtained from the cadavers used for dissection by the undergraduate medical students in the department of anatomy. The length of the basilar artery, variations in its course, level of formation and termination were noted. The variations in the caliber of right and left vertebral arteries and their symmetry were noted. Photographs were taken to document the variations. The results obtained were then tabulated.

Results: In the present study variations in the origin of basilar artery was noted in $25 \%$ of specimens. Other variations like fenestration and button hole formation was also noted. Asymmetry of vertebral arteries were present in $14 \%$ of specimens. Hypoplasia of vertebral artery was also noted.

Conclusion: Knowledge of variations in the vertebrobasilar system is helpful for the neurosurgeons to plan and execute surgeries for treatment of stenosis, aneurysms, and arteriovenous malformations in the posterior cranial fossa.
\end{abstract}

Keywords: Vertebrobasilar system, Variations, Hypoplasia, Asymmetry, Posterior circulation, Vertebrobasilar ischemia.

\section{Introduction}

The intracranial part of vertebral artery, basilar artery, and their branches together form the veretebrobasilar system. The vertebrobasilar system, also known as posterior circulation is an important vascular network that supplies blood to the posterior part of the cerebral hemispheres including occipital lobes and posterior portion of temporal lobes, cerebellum and brainstem. The vertebral arteries of both sides unite to form a basilar artery, a large median vessel, at the pontomedullary junction. It runs over the ventral surface of pons in a shallow median groove and terminates at the upper border of pons by dividing into right and left posterior cerebral arteries, which pass ventral to the respective oculomotor nerves. ${ }^{1}$

Anomalies and variations in the vertebrobasilar system has been reported in the previous studies. Normal morphology of the basilar artery is an essential component of cerebral circulation since the hindrance of blood supply due to any cause, even for a short duration (7-8 minutes) would cause severe and irreversible damage to brain cells. Anatomical variations in the morphology of the basilar artery is thought to be an aetiological factor for many clinicopathological conditions such as atherosclerosis, infarcts, arteriovenous malformations, transient ischemic attacks, and certain syndromes including wallenberg's syndrome, medial medullary syndrome and weber's syndrome. ${ }^{2}$

Fenestrations in the vertebrobasilar system is a factor which increases the incidence of aneurysms in this region. Ten percent of saccular aneurysms are located at the posterior circulation. ${ }^{3}$
Asymmetry of vertebral arteries are quite common, but the amount of blood reaching the basilar artery remains constant due to contralateral large vertebral artery. ${ }^{4}$ The hypoplasia / asymmetry of vertebral arteries are frequently associated with posterior circulation stroke. Identification of anomalies or variations in the vertebrobasilar system can be useful in diagnosing associated aneurysms, and in preventing complications during endovascular treatment. ${ }^{5,6}$

The aim of the present study is to find out variations in the origin and termination of basilar artery as well as variations in the size, shape and position of both intracranial part of vertebral and basilar arteries.

\section{Materials and Methods}

The study was conducted in 60 randomly selected brain specimens obtained from the cadavers used for dissection by the undergraduate medical students in the department of anatomy. Those specimens with gross pathological lesions of the brain were excluded. The specimens were then numbered and fixed in 10\% formalin for 10 days in the department of anatomy. The arachnoid mater was removed carefully. The basilar and vertebral arteries were dissected. The specimens were then dried and the vessels were painted using wet eosin pencil. The external diameter of the arteries were measured using a graduated calipers to record hypoplasia of the vessels (external diameter $<2 \mathrm{~mm}$ ). The length of the basilar artery, variations in its course, level of formation and termination were noted. The variations in the caliber of right and left vertebral arteries and their symmetry were noted. Photographs 
were taken to document the variations. The results obtained were then tabulated.

\section{Results and Discussion}

Basilar Artery: Basilar artery is a large median vessel formed by the union of right and left vertebral arteries at the pontomedullary junction. It runs along the median sulcus in the cisterna pontis over the ventral surface of pons and on reaching the ponto mesencephalic junction bifurcates into right and left posterior cerebral arteries. (Fig. 1)

The diameter of the basilar artery varied from 2$8 \mathrm{~mm}$ with a mean of $4.6 \mathrm{~mm}$. The length of the basilar artery varied from $25 \mathrm{~mm}-45 \mathrm{~mm}$ with a mean of $30.3 \mathrm{~mm}$. In no specimens hypoplasia or aplasia was noted. The variations in the level of origin and terminal bifurcation of basilar artery were looked for in all the 60 specimens. It was noted that origin was at the pontomedullary junction in 45 specimens $(75 \%)$ (Fig. $1)$; above the pontomedullary junction in 7 specimens (11.7\%) (Fig. 2) and below the ponto medullary junction in 8 specimens (13.3\%) (Fig. 3) and in no specimens hypoplasia or aplasia or complete duplication of the basilar artery was noted. In one specimen, a button hole formation was seen in the artery close to its origin (Fig. 2). In another specimen, a partial duplication of the artery was noted immediately after its formation at the pontomedullary junction (Fig. $5)$. The termination of basilar artery was noted at the pontomesencephalic junction in 53 circles $(88.3 \%)$ (Fig. $1)$ and at the mammillary bodies in 7 circles $(11.7 \%)$ (Fig. 4). Variations in the course of basilar artery was also noted. There are 3 types of courses of basilar artery reported in the literature- bent / curved course, straight \& ' $S$ ' shaped course. In the present study the straight and curved course were noted. The curved course was noted in 26 specimens (43.3\%) (Fig. 3). In no specimen ' $\mathrm{S}$ ' shaped course was found.

Vertebral Artery: The vertebral artery enters the cranial cavity through the foramen magnum, close to the anterolateral aspect of the medulla. They converge medially as they ascend the medulla and unite to form the midline basilar artery at the pontomedullary junction. It could be dissected out intact only in 50 specimens. Out of this, the arteries were found to be symmetrical in 43 specimens $(86 \%)$ (Fig. 1) and asymmetrical in 7 specimens (14\%) (Fig. 6) among the asymmetrical arteries, the right vertebral artery was found to be larger than the left in 4 specimens (8\%) and left vertebral artery was found to larger than the right in 3 specimens (6\%). Hypoplasia of the vertebral artery was observed in one specimen on the left side (Fig. 6). No non union or fenestration or absence of vertebral artery was noted.

Table 1: Comparison study of level of formation of basilar artery

\begin{tabular}{|c|c|c|c|}
\hline \multirow[t]{2}{*}{ Author (Year) } & \multicolumn{3}{|c|}{ Origin } \\
\hline & PM Jn & Above PM Jn & Below PM Jn \\
\hline Wojtowicz et al (1989) ${ }^{21}$ & $44.4 \%$ & $15.1 \%$ & $40.4 \%$ \\
\hline Akar et al $(1994)^{22}$ & $36.4 \%$ & $54.5 \%$ & $9.1 \%$ \\
\hline Shongur et al $(2008)^{3}$ & $20 \%$ & $12 \%$ & $67 \%$ \\
\hline Padmavathi et al (2011) & $44.4 \%$ & $16.7 \%$ & $38.9 \%$ \\
\hline Wankhede et al (2014) ${ }^{17}$ & $62.50 \%$ & $29 \%$ & $12.50 \%$ \\
\hline Kushwaha et al (2017) ${ }^{19}$ & $38.46 \%$ & $38.46 \%$ & $23.07 \%$ \\
\hline Present study & $75 \%$ & $11.7 \%$ & $13.3 \%$ \\
\hline
\end{tabular}

Table 2: Comparison study of level of termination of basilar artery

\begin{tabular}{|l|c|c|c|}
\hline \multirow{2}{*}{ Author (Year) } & \multicolumn{3}{|c|}{ Termination } \\
\cline { 2 - 4 } & Ponto mesencephalic Jn & Mammillary body & Upper pons \\
\hline Wojtowicz et al (1989) $)^{21}$ & $56 \%$ & $32.9 \%$ & $11.1 \%$ \\
\hline Saeki et al (1977) & $88 \%$ & $2 \%$ & $10 \%$ \\
\hline Wankhede et al (2014) ${ }^{17}$ & $50 \%$ & $32.50 \%$ & $17.50 \%$ \\
\hline Kushwaha et al (2017) & $53.84 \%$ & $38.46 \%$ & $7.69 \%$ \\
\hline Present study & $88.3 \%$ & $11.7 \%$ & Nil \\
\hline
\end{tabular}

Table 3: Comparison study of course of basilar artery

\begin{tabular}{|c|c|c|c|}
\hline Authors (year) & Straight course & Curved course & 'S' shaped course \\
\hline Pai et al $(2007)^{18}$ & $48 \%$ & $52 \%$ & nil \\
\hline Mehinovic et al $(2014)^{24}$ & $30 \%$ & $46.6 \%$ & $23.3 \%$ \\
\hline Wankhede et al (2014) ${ }^{17}$ & $55 \%$ & $37.5 \%$ & $5 \%$ \\
\hline present study & $56.7 \%$ & $43.3 \%$ & nil \\
\hline
\end{tabular}


Table 4: Variations of vertebral artery as observed by other workers

\begin{tabular}{|l|c|c|c|}
\hline \multirow{2}{*}{ Author (Year) } & \multirow{2}{*}{ Symmetrical } & \multicolumn{2}{c|}{ Asymmetrical } \\
\cline { 3 - 4 } & & RT $>$ LT & LT $>$ RT \\
\hline Stopford 1915) & & $41 \%$ & $51 \%$ \\
\hline Akar et al (1994) & $8 \%$ & $45.4 \%$ & $18.2 \%$ \\
\hline Pai et al (2007) & $36.4 \%$ & $40 \%$ & $6.7 \%$ \\
\hline Present study & $53.3 \%$ & $8 \%$ & $6 \%$ \\
\hline
\end{tabular}

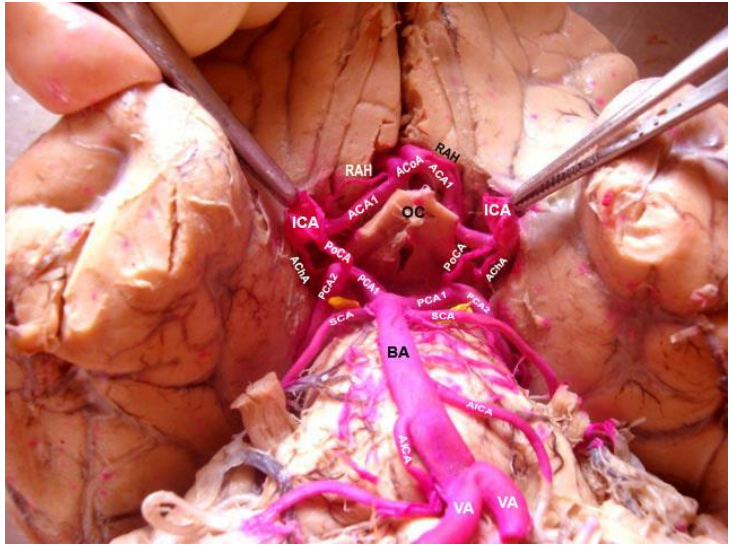

Fig. 1: Base of brain showing origin of basilar artery at pontomedullary junction and termination at pontomesencephalic junction. (BA - Basilar artery, VA-Vertebral artery, PCA1-Precommunicating segment of posterior cerebral artery, SCA-Superior cerebellar artery, AICA-Anterior imnferior cerebellar artery, PCA2-Postcommunicating segment of posterior cerebral artery, ICA -Internal carotid artery)

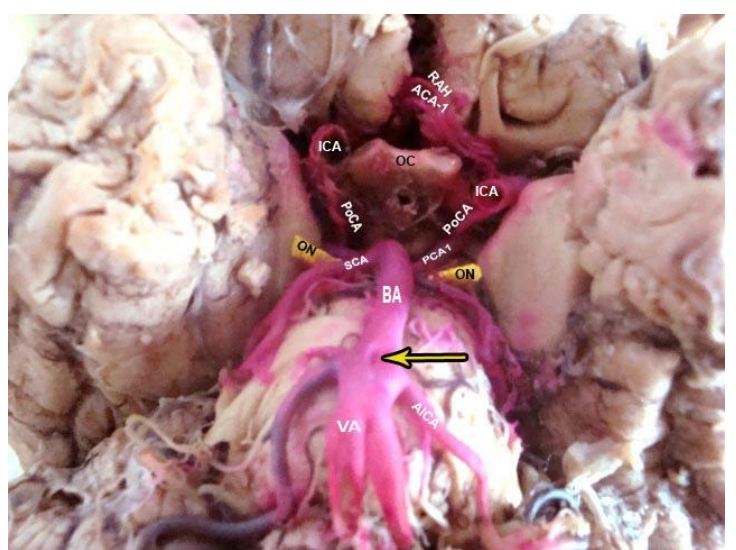

Fig. 2: Base of brain showing origin of basilar artery above the pontomedullary junction. Arrow is showing a button hole formation in the proximal part of basilar artery

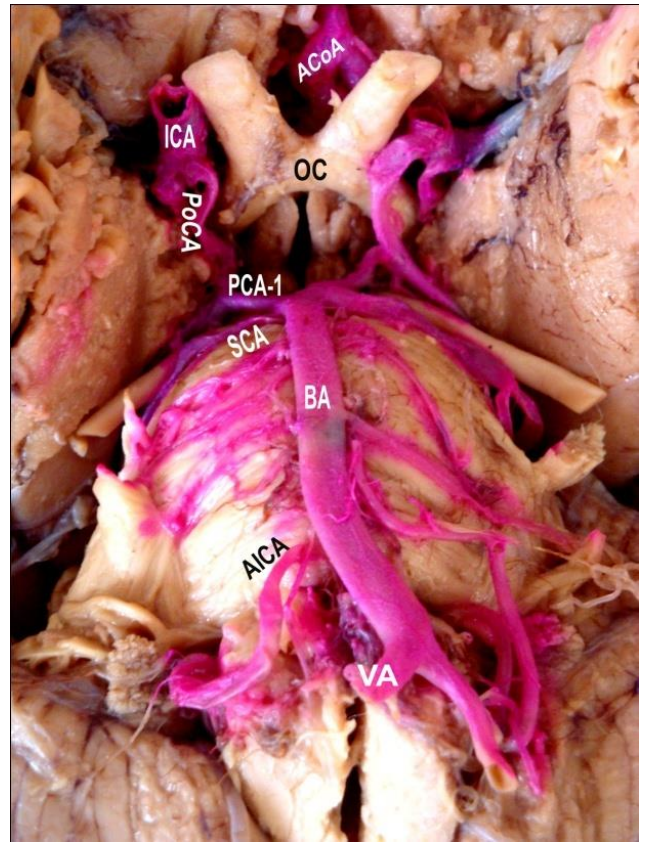

Fig. 3: Base of brain showing origin of basilar artery (BA) below the pontomedullary junction and a curved course of basilar artery

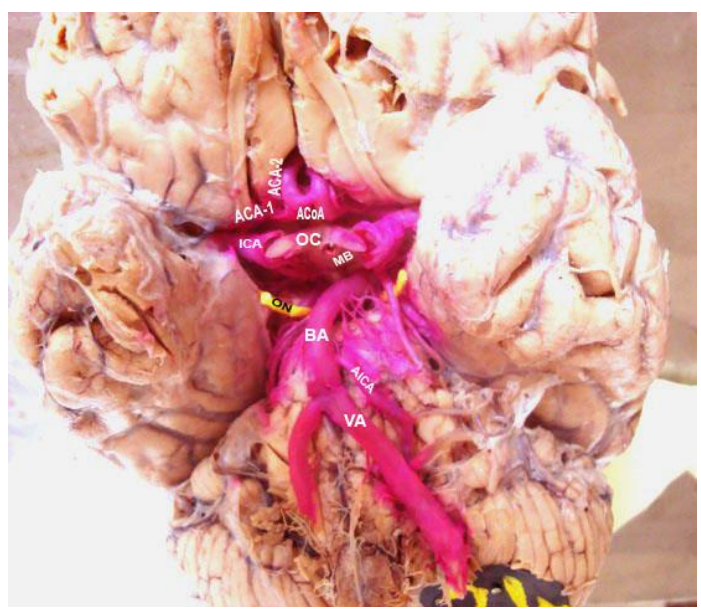

Fig. 4: Base of brain showing termination of basilar artery (BA) at mammillary bodies 


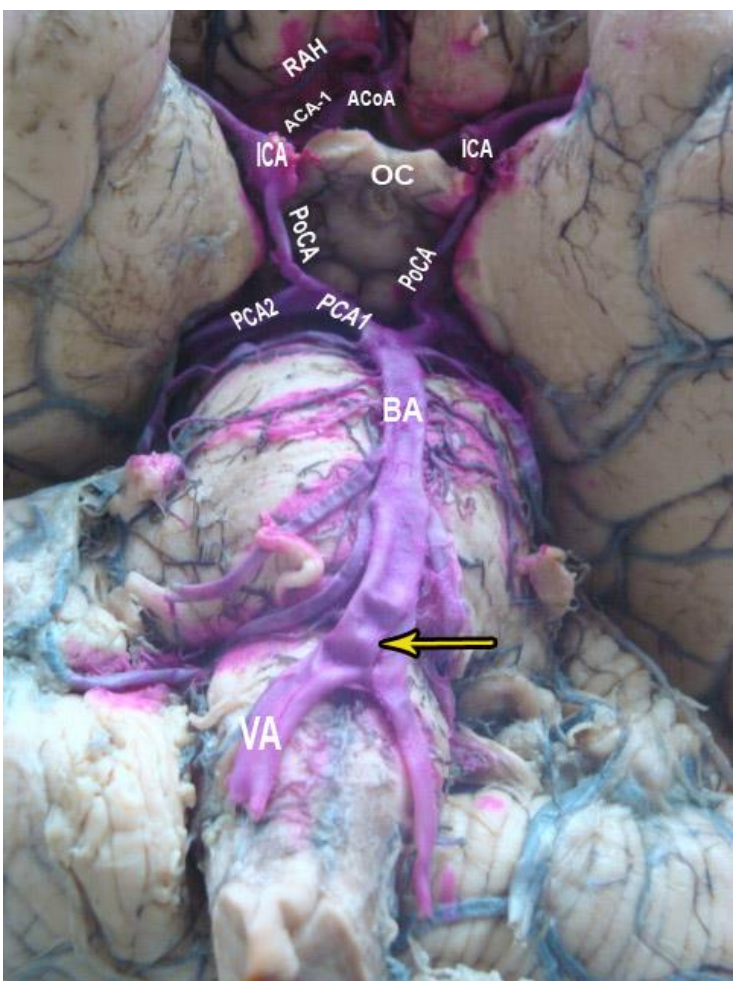

Fig. 5: Base of brain showing a fenestration at the proximal part of basilar artery

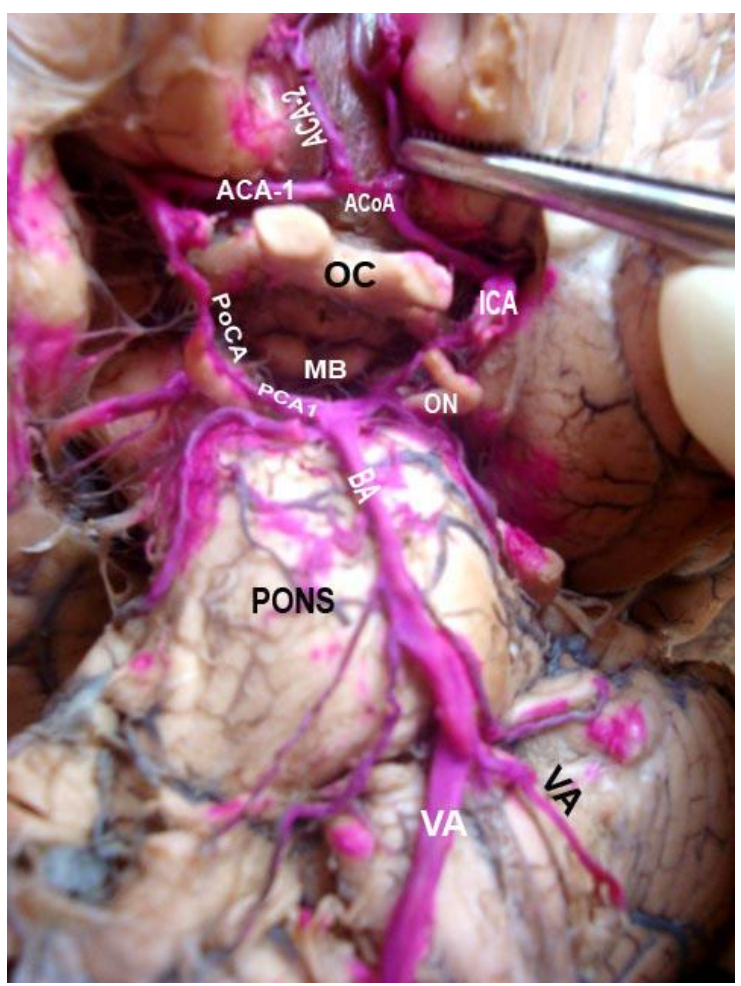

Fig. 6: Base of brain showing asymmetric vertebral arteries with hypoplastic vertebral artery (VA) on the left side

\section{Discussion}

Anomalies of basilar artery are rare and include most commonly duplication or fenestration and so rarely hypoplasia, segmental aplasia, plexiform appearance etc. ${ }^{7}$ In the present study there was no basilar artery hypoplasia noted.

In the present study, basilar artery duplication was noted in 1 specimen in the lower half immediately after the union of vertebral arteries. The incidence of duplication / fenestration of basilar artery ranges from 1.3 to $5.26 \%$ in postmortem studies and from 0.022 to $0.6 \%$ in angiographic reports. It occurred most commonly in the lower half of the vessel. ${ }^{8,9}$

In 2002 Masanori Tsutsumushi et al reported a case of duplication of distal part of basilar artery. ${ }^{10}$ Tran Dinh et al (1991) noted duplication of basilar artery at the union of two vertebral arteries and partial duplication in the upper portion of the artery. ${ }^{11}$

Complete duplication of basilar artery, with each vertebral artery continuing separately to form a posterior cerebral artery has been described previously by Adachi (1928) ${ }^{12}$ and Yasargil (1982). ${ }^{13}$ Ten percent of saccular aneurysms are located in the posterior circulation. Fenestration/duplication in the vertebrobasilar system is a factor which increases the incidence of aneurysms in this region. Anatomic hemodynamic changes at the proximal ends of fenestrations may cause intracranial saccular aneurysms. ${ }^{14}$

Basilar artery hypoplasia was not noted in the present study. Basilar artery is said to be hypoplastic if its diameter is less than $2 \mathrm{~mm}$. Hegedius (1985) opined that hypoplasia of the basilar artery is rarely encountered variation of the vertebrobasilar system and frequently accompanied by hypoplastic vertebral Artery. He demonstrated autopsy findings of 3 cases of entire basilar artery hypoplasia associated with vertebral artery hypoplasia in which two of the deceased had neurological symptoms characteristic of insufficiency in the vertebrobasilar system. ${ }^{15}$

According to Chathurvedi et al (1999) hypoplastic vertebrobasilar vessels should be considered among the potential causes of cerebral ischemia in young adults. ${ }^{16}$

The data on the length and diameter of the basilar artery is important for interventional radiologist to perform various endovascular procedures and also to the neurosurgeons to get proper approach to the surgery. ${ }^{17}$ In the present study the diameter of the basilar artery varied from $2-8 \mathrm{~mm}$ with a mean of $4.6 \mathrm{~mm}$ and the length of the basilar artery varied from $25 \mathrm{~mm}-45 \mathrm{~mm}$ with a mean of $30.3 \mathrm{~mm}$. Pai et al (2007) reported that the diameter of basilar artery varied from $3-7 \mathrm{~mm}$ (mean $4.3 \mathrm{~mm}$ ) and the length varied from 24 $35 \mathrm{~mm}$ (mean 24.9mm). ${ }^{18}$ Kushwaha et al (2017) reported that the length of basilar artery varied from 24 $-40 \mathrm{~mm}$ and the mean length was $29.72 \mathrm{~mm}$ and an overall mean diameter of $4.3 \mathrm{~mm} .{ }^{19}$ Idowu et al (2010) observed that the diameter of basilar artery was 
relatively constant throughout its course with few minor variations. ${ }^{20}$

Variation in the level of origin and termination of basilar artery has been noted by previous workers. In the present study, basilar artery most commonly arose at the pontomedullary junction (PM Jn) and terminated at the level of pontomesencephalic junction. Basilar artery arose above the pontomedullary junction (PM Jn) in $11.7 \%$ cases and below the junction in $13.3 \%$ cases. Its termination at the level of mammillary body in the interpeduncular fossa was observed in $11.7 \%$ cases.

The position of termination of basilar artery also determines the type of approach to be taken for the treatment of aneurysms of the basilar apex and those involving the posterior cerebral arteries, as efforts need to be made to minimize or prevent damage to nearby important structures such as the mammillary body or optic chiasma. $^{2}$

Regarding the course of basilar artery, normally it has a straight course. Other than that a curved and an ' $S$ ' shaped course also has been reported in the previous literature. In the present study in $56.7 \%$ of specimens basilar artery had a straight course and in $43.3 \%$ of specimens it had a curved course. No ' $\mathrm{S}$ ' shaped course was noted. In the present study, a button hole on the proximal part of basilar artery was observed in one case. Stopford (1915) and Blackburn (1907) reported cases with a small foramen immediately above the origin of basilar artery. ${ }^{25,26}$

Vertebral Artery: The vertebral arteries were observed for any asymmetry, hypoplasia and fenestration. The paired arteries are said to be asymmetric if one of them is twice the diameter of the opposite artery.

In the present study, vertebral arteries were symmetrical in $86 \%$ of cases and asymmetrical in $14 \%$ of cases. It was noted that the right vertebral artery is frequently larger than the left vertebral artery. Akar et al (1994) also observed right vertebral artery larger than the left. ${ }^{22}$ Paksoy et al (2004), ${ }^{27}$ Jeng et al (2004), ${ }^{28}$ Kazui et al (1989) ${ }^{29}$ reported that left vertebral artery was usually larger than the right vertebral artery.

It has been reported that unequal diameters of the Vertebral Arteries cause insufficiency in the vertebrobasilar circulation, which in turn results in vertebrobasilar ischemia. Asymmetry of the intracranial parts of vertebral arteries is common and vertebral artery asymmetry leads to basilar deviation. ${ }^{27}$

Congenital Vertebral artery hypoplasia is an uncommon embryonic variation of the posterior circulation. The frequency of the hypoplasia has been reported to range from $2 \%$ to $6 \%$ based on autopsy studies and angiograms. ${ }^{28}$

The definition of vertebral artery hypoplasia has not been precisely stated. Vertebral arteries less than $2 \mathrm{~mm}$ diameter are accepted as hypoplastic in pathoanatomic studies. In ultrasonographic studies, frequency of hypoplasia was reported as $1.9 \%$ considering the vertebral artery diameter less than $2 \mathrm{~mm}$ as hypoplastic and $6 \%$ in the cases that have a cut off value of $3 \mathrm{~mm}$ diameter. ${ }^{30}$

In the present study, hypoplasia of vertebral artery was noted $(<2 \mathrm{~mm})$ in $4 \%$ cases. It was not associated with the hypoplasia of basilar artery.

Park et al (2007) reported that hypoplastic vertebral artery is frequent in patients with posterior circulation stroke. People with hypoplastic vertebral artery may have a high probability of posterior circulation stroke, with atherosclerotic susceptibility and ipsilateral lesions in the vertebral artery territory. ${ }^{5}$

Uzmansel et al (2009) reported a case of hypoplastic left vertebral artery accompanying an aneurysm at the distal end of basilar artery.$^{30}$ Chuang et al (2006) reported that hypoplastic vertebral artery might cause a decrease in the net flow volume which conditions the development of ischemic stroke in posterior cerebral circulation. ${ }^{31}$ In addition hypoplastic vertebral artery with additional risk factors such as hypertension, hyperlipidemia, diabetes, and smoking was also reported to contribute to ischemic brainstem stroke, even in young patients. ${ }^{32}$

Fenestration or non-unions of Vertebral Arteries were not observed in the present study. Stopford $(1915)^{25}$ and Tran Dinh et al $(1991)^{11}$ reported cases of Fenestrations of vertebral artery in their study.

\section{Conclusion}

In the present study the origin of basilar artery was observed in $13.3 \%$ of specimens below the pontomedullary junction and in $11.7 \%$ of the specimens above the pontomedullary junction. In no specimens hypoplasia or aplasia or complete duplication of the basilar artery was noted. In one specimen a button hole formation was seen in the basilar artery close to its origin. In another specimen a partial duplication of the artery was noted immediately after its formation at the pontomedullary junction. In $11.7 \%$ of cases the termination of basilar artery was noted at the mammillary bodies. The vertebral artery was noted to be asymmetrical in $14 \%$ of the specimens. Most commonly the right vertebral artery was larger than the left. The artery was observed to be hypoplastic in $4 \%$ of cases. Unequal diameters of the Vertebral Arteries cause insufficiency in the vertebrobasilar circulation, which in turn results in vertebrobasilar ischemia. Knowledge of variations in the vertebrobasilar system is helpful for the neurosurgeons to plan and execute surgeries for treatment of stenosis, aneurysms, and arteriovenous malformations in the posterior cranial fossa.

\section{References}

1. Williams PL, Dyson M, Collins P, Bannister, eds. Gray's Anatomy. $40^{\text {th }}$ ed. New York: Churchill Livingstone, 1995:390,1984.

2. Padmavathi G, Rajeshwari T, Niranjana Murthy KV. Study of the variations in the origin and termination of basilar artery. Anatomica Karnataka. 2011;5:54-9. 
3. Songur A, Gonul Y, Ozen OA, Kucuker H, Uzun I, Bas $\mathrm{O}$, Toktas M. Variations in the intracranial vertebrobasilar system. Surg Radiol Anat. 2008;30:25764.

4. Gillilan LA. Anatomy and embryology of the arterial system of the brainstem and cerebellum. In: Vinken PJ, Bruyn GW (editors), Handbook of clinical neurology, Amsterdam, Netherlands, 1975, pp.24-44.

5. Park JH, Kim JM, Roh JK. Hypoplastic vertebral artery: Frequency and associations with ischemic stroke territory. J Neurol Neurosurg Psychiatry. 2007;78:95458 .

6. Perren F, Poglia D, Landis T, Sztajzel R. Vertebral artery hypoplasia a predisposing factor for posterior circulation stroke? Neurology. 2007;68:65-67.

7. Pekindil G, Bayar C. Solated hypoplasia of distal basilar artery: clinical and imaging findings. Yeni Symposium. 2004;42(2):121-25.

8. Hoffman WF, Wilson CB. Fenestrated basilar artery with an associated saccular aneurysm. Case report. $J$ Neurosurg. 1979;50:262-64.

9. Takahashi M, Tamakawa Y, Kishikawa T, Kowada M. Fenestration of the basilar artery. Report of three cases and review of the literature. Radiology. 1973;109: 79-82.

10. Tsutsumi M, Kazekawa K, Tanaka A, Ueno Y, Nomoto Y. Duplication of distal part of basilar artery. Case report. Radiation Medicine. 2002;20(5):265-67.

11. Tran-Dinh HD, Soo YS, Jayasinghe LS. Duplication of the vertebra-basilar system. Australas Radiol. 1991;35(3):220-24.

12. Adachi B. Das Arteriensystem der Japaner, vol. 1, Kyoto, Japan: Kaiserlich-japanischen Univeritat zu Kyoto;1928. Cited by Jonas et al in Complete duplication or extreme fenestration of the basilar artery.1999. American Journal of Neuroradiology. 1999;20:149-150.

13. Yasargil MG and Smith RD. Management of aneurysms of anterior circulation by intracranial procedures. Youmans JR (ed). Neurological Surgery, ed 2. Philadelphia: WB Saunders; 3:1663-1696;1982.

14. Stehbens WE. Etiology of intracranial berry aneurysms. $J$ Neurosurg. 1989;70:823-31.

15. Hegedius K. Hypoplasia of basilar artery. Eur Arch Psychiatr Neurol Sci. 1985;234:395-98. Cited by Pekindil $\mathrm{G}$ in Solated hypoplasia of distal basilar artery: clinical and imaging findings. Yeni Symposium. 2004;42(2):121125.

16. Chathurvedi S, Lukovits TG, Chen W, Gorelick PB. Ischemia in the territory of a hypoplastic vertebrobasilar system. Neurology. 1999;52:980-983.

17. Wankhede AH, Hosmani PB, Dipti AN. Morphological study of the basilar artery in adult human cadavers. Int $J$ Anat Res. 2014;2(3):497-502.

18. Pai B.S, Varma R.G, Kulkarni R.N, Nirmala S, Manjunath L.C, Rakshith S. Microsurgical anatomy of the posterior circulation. Neurol India. 2007;55(1):31-41.

19. Kushwaha RK, Dubey AK, Prasad R, Ranjan R. Study of morphology of basilar artery in Jharkhand population. Journal of Dental and Medical sciences. 2017;16(9):1721.

20. Idowu OE, Mlomo AO, Akang EU. Surgical anatomy of the vertebrobasilar territoryand posterior circle of Willis. West Afr J Med. 2010;29:230-34.

21. Wojtowicz Z, Zaluska S, Kis G, Sawa J. The basilar artery of humans. Ann Univ Mariae Curie Sklodowska Med. 1989;44:101-108.

22. Akar ZC, Dujovny M, Slavin KV, Gomez- Tortosa E, Ausman JI. Microsurgical anatomy of the intracranial part of the vertebral artery. J Neurosurg. 1994;16(3):171-180.
23. Saeki N, Rhoton AL. Microsurgical anatomy of the upper basilar artery and the posterior circle of Willis. $J$ Neurosurg. 1977;46:563-578.

24. Mehinovic A, Isakovic E, Delic J. Variations in the position and shape of the basilar artery. OA Maced J Med Sci. 2014;2(3):421-23.

25. Stopford JSB. The arteries of the Pons and medulla oblongata. J Anat Physio. 19151;50:131-164.

26. Blackburn I.W. Anomalies of the encephalic arteries among the insane. A study of the arteries at the base of the encephalon in two hundred and twenty consecutive cases of mental disease, with special reference to anomalies of the circle of Willis J Comp Neurol. 1907; 17;493-517. Cited by Stopford in The arteries of the Pons and medulla oblongata. J Anat Physiol. 1915;50:131-164.

27. Paksoy Y, Vatansev H, Seker M, Ustun ME, Buyukmumku M, Akpinar Z. Congenital morphological abnormalities of the distal vertebral arteries and their relationship with vertigo and dizziness. Med Sci Monit. 2004; 10:316-23.

28. Jeng JS, Yip PK. Evaluation of vertebral artery hypoplasia and asymmetry by color coded duplex ultrasonography. Ultrasound Med Biol. 2004;30:605-9.

29. Kazui S, Kuriyama Y, Naritomi H, Sawada T, Ogawa M, Maruyama M. Estimation of vertebral artery asymmetry by computed tomography. Neuroradiology. 1989;31:23739.

30. Uzmansel D, Kurtoglu Z, Bagdatoglu C, Kara A, Yildiz A Unilateral variant vertebral artery with an aneurysm of the basilar tip: a case report. International Journal of Anatomical Variations. 2009;2:96-98.

31. Chuang YM, Huang YC, Hu HH, Yang CY. Toward a further elucidation: role of vertebral artery hypoplasia in acute ischemic stroke. Eur Neurol. 2006;55:193-97.

32. Giannopoulos S, Markoula S, Kosmidou M, Pelodou SH, Kyritsis AP. Lateral medulllary ischemic events in young adults with hypoplastic vertebral artery. $J$ Neurol Neurosurg Psychiatry. 2007;78:987-89.

How to cite this article: Narayanan S, Geetha GN. A cadaveric study of variations in the vertebrobasilar system. Indian J Clin Anat Physiol. 2018;5(4):553-558. 